\title{
Continuous Glucose Monitoring: Effects on Metabolic Control, Fear and Frequency of Hypoglycaemic Episodes
}

\author{
H S Moore ${ }^{1}$, A Soni ${ }^{1}$, M Clemente ${ }^{1}, \mathrm{~S} \mathrm{M} \mathrm{Ng}^{1}$.
}

1. Southport and Ormskirk Hospital NHS trust.

Authors declare no conflict of interest

\section{Introduction}

Self-monitoring of blood glucose (SMBG) is an important part of diabetes management. ${ }^{1}$

Continuous glucose monitoring (CGM) provides real-time measurement of users' glucose levels. The advantage of CGM is the availability of constant information about glucose levels which helps to predict hyper and hypoglycaemia and to adjust the insulin doses accordingly.

NICE guidelines recommend that children and young people with type 1 diabetes and persistent problems with hypoglycaemia unawareness or repeated hyper or hypoglycaemia should be offered CGM. ${ }^{2}$

In UK there is limited funding for CGM due to lack of evidence for benefits of use over SMBG in improving control. In our service within a large DGH, we have a cohort of 12 children who were funded for CGM use over a minimum of 12 months.

\section{Aim}

To assess the effects of CGM on metabolic control, fear and frequency of hypoglycaemic episodes and assess the overall compliance over a period of 12 months.

\section{Method}

Data collected for 12 patients on HBA1C and frequency of hypoglycaemic episodes. Patients aged over 12 years and parents were asked to complete fear of hypoglycaemia questionnaires for before and after CGM use.

\section{$\underline{\text { Results }}$}

12 patients (8males), with median age 14.5 years (5-18 years) used CGM over a year.

- There were some issues with non-compliance in $58 \%$ of patients.

- Results for $\mathrm{HbA1C}$, frequency of hypoglycaemic episodes for all and fear of hypoglycaemia scores for 10 patients are shown below

Table 1. Comparison of $\mathrm{HbA} 1 \mathrm{c}$

\begin{tabular}{|l|l|l|l|l|}
\hline $\mathrm{n}=12$ & $\begin{array}{l}\text { Mean (SD) } \\
\text { DCCT } \%\end{array}$ & $\begin{array}{l}\text { Mean (SD) } \\
\mathrm{mmol} / \mathrm{mol}\end{array}$ & $\begin{array}{l}\text { 95\% Confidence } \\
\text { Interval }\end{array}$ & $\mathrm{p}$ - Value \\
\hline $\begin{array}{l}\text { Pre- CGM } \\
\text { HbA1c }\end{array}$ & $8.6(1.2)$ & $70.7(13.4)$ & & \\
\hline 1 months & $7.5(0.9)$ & $59.3(10.9)$ & $3.6-19.1$ & $<0.01$ \\
\hline 3 months & $7.6(1.2)$ & $60.0(12.9)$ & $2.8-18.6$ & 0.012 \\
\hline 6 months & $7.7(1.0)$ & $60.5(11.0)$ & $-0.56-21.1$ & 0.061 \\
\hline 9 months & $7.6(0.4)$ & $59.8(4.2)$ & $1.92-20.0$ & 0.022 \\
\hline 12 months & $8.0(0.9)$ & $64(9.6)$ & $-2.9-16.4$ & 0.15 \\
\hline
\end{tabular}

\section{Discussion}

We found a significant improvement in $\mathrm{HbA} 1 \mathrm{c}$ within 1 month of usage and that improvement was sustained over 9 months but not over the full year. This initial improvement is in agreement with a previous study by BukaraRadujković et al which investigated how short term use of CGM may improve long-term prognosis in paediatric patients with T1DM. ${ }^{3}$

Bukara-Radujković found that hypoglycaemic episodes were decreased, which was also reported by Davey et al in 2010 which is in contrast to our results. ${ }^{3,4}$ We found that the number of hypoglycaemic episodes increased significantly at 6 months of usage but at 12 months there was no significant difference. The initial increase in hypoglycaemic episodes is hypothesised to be due to an increase in metabolic control. Furthermore the contrast with previous publications may be due to the previous studies only using CGM for a shorter period of 72 hours whereas our participants used CGM for up to 12 months.

The improvement seen in fear of hypoglycaemia scores seen is statistically significant for both Behaviour and worry scores as well as the total score and is also in agreement with previous publications. Walker and Yucha reported an improvement in both fear of hypoglycaemia and quality of life with use of CGMS over a 12 week period in $2014 .{ }^{5}$

\section{Conclusion}

- CGM use improved metabolic control initially but this was not sustained over the full 12 months.

- Number of hypoglycaemic episodes may increase initially due to improved metabolic control but reduction in fear of hypoglycaemia is significant.
Table 2. Hypoglycaemic episodes

\begin{tabular}{|l|l|l|l|}
\hline$n=12$ & Mean (SD) & $\begin{array}{c}95 \% \text { Confidence } \\
\text { Interval }\end{array}$ & $p$ - Value \\
\hline 1 months & $1.66(1.3)$ & & \\
\hline 3 months & $3.1(3.1)$ & $-2.96-0.02$ & 0.052 \\
\hline 6 months & $4.9(3.7)$ & $-5.26--1.12$ & $<0.01$ \\
\hline 9 months & $5.3(3.3)$ & $-6.85-0.28$ & 0.065 \\
\hline 12 months & $3.8(2.7)$ & $-5.11-1.56$ & 0.239 \\
\hline
\end{tabular}

Table 3. Fear of hypoglycaemia

$n=10$ Before After p-value

\begin{tabular}{l|l|l|l} 
Mean Behaviour Score & 37.4 & 25.3 & $<0.01$
\end{tabular}

\begin{tabular}{|l|l|l|l} 
Mean Worry Score & 58.1 & 42.3 & $<0.01$
\end{tabular}

\begin{tabular}{l|l|l|l} 
Mean Total Score & 96.1 & 69.9 & $<0.01$
\end{tabular}

\section{References}

1. Haller MJ, Stalvey MS, Silverstein JH. Predictors of control of 2004:144:660-1.

2. NG18. Diabetes (type 1 and type 2) in children and young

3. Bukle: diagnosis and management. In: NICE, ed.2015. Bukara-Radujković G1, Zdravković D, Lakić S. Short-term use of in young type 1 diabetes mellitus patients in the long run: a
clinical trial. Vojnosanitski Pregled. 2011 Aug;68(8):650-4. Davey RJ, Jones TW, Fournier PA. Effect of Short-Term Use of Continuous Glucose Monitoring System with a Real-Time Glucose Display and a Low Glucose Alarm on incidence and Duration of Hypoglycemia in a Home Setting in Type 1 Diabetes
Mellitus. Journal of Diabetes Science and Technology. 2010;4(6): 1457-1464.

5. Walker TC, Yucha CB. Continuous Glucose Monitors: Use of Waveform Versus Glycemic Values in the Improvements of Glucose Control, Quality of Life, and Fear of Hypoglycemia. Journal of Diabetes Science and Technology. 2014;8(3):488-493.
doi:10.1177/1932296814528434. 